\title{
Uma nação para ser vista: desvelando o tempo e o espaço nacionais por meio da cor local na historiografia oitocentista
}

\author{
Eduardo Wright Cardoso*
}

\section{RESUMO}

Se durante o século XIX a escrita da história adquire contornos mais precisos, é importante reconhecer o papel da cor local neste processo. O dispositivo assegura, por um lado, o caráter nacional das produçóes intelectuais e, por outro, oferece meios de legitimação e fidelidade para as narrativas do período. $\mathrm{O}$ escopo deste artigo é, pois, não somente reafirmar a associação entre a cor local e a nação, mas sugerir possibilidades de apreensão do dispositivo e, sobretudo, discorrer sobre as implicaçôes e efeitos de seu emprego na elaboração da historiografia. Para isso, recorre-se tanto às prescrições relativas à cor local no contexto francês quanto aos textos da Revista do IHGB e de Varnhagen. Sugere-se, como hipótese, que a cor local é parte do vínculo que se estabelece entre tempo e espaço neste momento, além de possibilitar, devido à sua origem pictural, a criaçáo de uma imagem da nação.

Palavras-chave: Cor local; escrita da história; historiografia brasileira; Francisco Adolfo de Varnhagen; literatura.

\section{ABSTRACT}

Whether during the nineteenth century the writing of History acquires more precise contours, it is imperative to recognize the role of local color in this process. On one hand, the local color ensures the national character of intellectual productions and, on the other, it offers a means to legitimize the period's narratives. The scope of this article is not only to reaffirm the association between local color and nation, but also to suggest possibilities to apprehend the the local color and, above all, to discuss its implications and effects on the historiography development. To this end are used the texts about local color in the French context, and the texts of the Revista of IHGB and Francisco Adolfo de Varnhagen. As a hypothesis, the article suggests that local color is part of the link established between time and space in the moment, and that, due to its pictorial origin, it also contributes to the construction of a nation's image. .

Keywords: Local color; writing of history; Brazilian historiography; Varnhagen; literature.

DOI - http://dx.doi.org/10.1590/2237-101X016031006

Artigo recebido em 20 de abril de 2015 e aprovado para publicação em 10 de setembro de 2015.

* Mestre em História pela Universidade Federal de Ouro Preto (UFOP) e doutorando em História na Pontifícia Universidade Católica do Rio de Janeiro (PUC-Rio). Paris, Île-de-France, França. E-mail: edowc@yahoo.com.br. 
Estudos recentes sobre a cor local tendem a apontar a imprecisão teórica e analítica que acompanha esse dispositivo narrativo. ${ }^{1}$ Embora largamente empregada, seja nos escritos de caráter literário, seja na produção historiográfica durante o século XIX, a cor local permanece um objeto vago e, acrescento, marcado muitas vezes por uma abordagem apenas intuitiva. No entanto, o dispositivo revela-se fundamental para os esforços relativos à constituição da nação e da nacionalidade. O objetivo deste artigo, pois, é sugerir tanto uma alternativa que permita apreender e avaliar seu emprego quanto mapear seus usos e efeitos em textos literários e, principalmente, historiográficos durante o período oitocentista. Tentarei então esboçar uma interlocução mais intensa entre a escrita literária e a historiografia, na medida em que é da literatura que provêm as principais tentativas de regular seu uso. Ao retomar as poucas prescriçôes acerca da cor local provenientes das letras é possível, creio, compreender as potencialidades do dispositivo na escrita da história. Mais do que apenas sugerir sua importância para a produção intelectual desse período, intentarei demonstrar de que forma a cor local se apresenta como um instrumento fundamental para os literatos e para os historiadores que buscaram refletir sobre a nação.

$\mathrm{O}$ artigo, então, está organizado em três momentos: inicialmente, procuro estabelecer os vínculos entre a cor local e o tema da naçáo que se estabelece durante o século XIX. Afinal, é nesse período que a questão nacional ganha evidência. Em seguida, busco tratar, de forma pormenorizada, de duas dimensóes do dispositivo narrativo: o tempo e o espaço. Assim, relato as tentativas de definição de uma cronologia para o Brasil e, ademais, as sugestôes apresentadas para os possíveis começos da história nacional. Por fim, destaco como a delimitação territorial se revela um meio importante para a obtenção da integração nacional e, por isso, requer investimentos dos intelectuais desse período. Na escrita da história, enfim, a cor local é empregada como um instrumento que visa a organizar a temporalidade da historiografia referente à nação e, simultaneamente, mapear e desvelar seu território.

\section{A nação e a cor local}

A fim de sugerir uma acepção mínima para a cor local é imperativo recorrer às reflexôes oitocentistas que versaram exclusivamente sobre o dispositivo. Embora esparsas e restritas, elas contribuem para a construção de um entendimento mais preciso e acabado acerca dele. Aqui, portanto, é fundamental contemplar o discurso literário da primeira metade do século XIX. Afinal, o dispositivo tem na poesia e, sobretudo, na dramaturgia dois campos de desenvolvimento significativos. De acordo com Carine Fluckiger: "A pesquisa da 'cor local' no

\footnotetext{
${ }^{1}$ FLUCKIGER, Carine. L'histoire entre art et science: la "couleur locale" chez Thierry et Barante. Mémoire de licence. Université de Genève, 1995, p. 1, e KAPOR, Vladimir. Local colour: a travelling concept. Bern: Peter Lang AG, 2009, p. 1.
} 
teatro está na ordem do dia devido ao apelo dos românticos (tanto realistas quanto liberais) para a criação de uma 'tragédia histórica', semelhante à 'Marie Stuart' de Schiller [...]”. ${ }^{2}$

Objeto de discussóes intensas nas primeiras décadas do século XIX, o teatro conhece uma dupla evolução nesse período: por um lado, se percebe uma maior atenção à "exatidão" histórica dos costumes e, por outro, os dramas se orientam para um tipo de realismo que tende a assegurar a especificidade do objeto narrado e de seu meio. ${ }^{3}$ Esse desenvolvimento contempla ainda uma evolução nos procedimentos técnicos teatrais. ${ }^{4} \mathrm{O}$ intuito desse investimento é aumentar o poder de ilusão sobre o espectador, e tais modificações atingem inclusive o papel do dramaturgo. $\mathrm{O}$ escritor adquire poderes quase ilimitados de reprodução da vida e fidelidade ao "real". De acordo com Madame de Staël, o escritor:

[...] pode evocar o passado, ou fazer reaparecer o presente na medida em que emprega expressóes consoantes ou náo ao país que ele canta, na medida em que observa ou negligencia as cores locais e essas pequenas circunstâncias engenhosamente inventadas que levam o espírito, seja na ficção ou na realidade, a descobrir a verdade sem que ela seja dita. ${ }^{5}$

Assim, o emprego de expressóes características ao país narrado, a fidelidade às cores locais de uma determinada nação, os detalhes incorporados à narrativa produzem e alcançam a verdade. Essa fidelidade, contudo, não está restrita à abordagem do presente. $\mathrm{O}$ escritor pode reproduzi-lo com precisão, mas lhe é possível também mobilizar esses componentes para ressuscitar o passado. Como se percebe, pois, o escritor dispóe de dispositivos, como a cor local, que lhe possibilitam representar a realidade em todos seus meandros e, além disso, manipular o tempo. Aliás, é justamente essa pretensão de reproduzir a integralidade que explica, segundo Fluckiger, o sucesso da cor local nesse momento. Nas suas palavras:

O ideal que subjaz à noção de "cor local", com efeito, é aquele da "vida" ou da "realidade" fielmente reproduzida. O artista se atribui, nesse sentido, os dons de um observador quase

\footnotetext{
${ }^{2}$ FLUCKIGER, C. L'histoire entre art et science, op. cit., p. 26. "La recherche de la "couleur locale" au théâtre est à l'ordre du jour, dans la mesure où les romantiques (tant royalistes que libéraux) en appellent à la constitution d'une "tragédie historique", à l'instar de la Marie Stuart de Schiller [...]". Procurei preservar a grafia original na transcriçấo de todas as fontes deste estudo. Para as referências em outras línguas, ademais, utilizei uma tradução livre.

${ }^{3}$ Ibid., p. 30-31.

${ }^{4}$ No contexto nacional ocorre um processo análogo, ou seja, a discussão sobre o teatro, mais precisamente sobre a peça $O$ jesuita, de José de Alencar, também enseja reflexóes sobre a cor local. A polêmica, travada entre Joaquim Nabuco e Alencar, tem início a partir do fracasso de público da peça. Cf: COUTINHO, Afrânio (Org.). A polêmica Alencar/Nabuco. Rio de Janeiro: Tempo Brasileiro; Brasília: Editora UnB, 1978.

${ }^{5}$ STAËL apud FLUCKIGER, C. L'histoire entre art et science, op. cit., p. 29. "il peut évoquer le passé, ou faire reparaitre le présent selon qu'il se sert d'expressions conformes ou non au pays qu'il chante, selon qu'il observe ou néglige les couleurs locales et ces petites circonstances ingènieusement inventées qui exercent l'esprit, dans la fiction comme dans la realité, à découvrir la vérité sans qu'on vous la dise”.
} 
ilimitados, na medida em que pode "ver" a "realidade" em toda a sua multiplicidade, atravessar as fronteiras — geográficas e mentais — e ainda, pelo poder "mágico" de sua imaginação, viajar no tempo. ${ }^{6}$

As propriedades associadas à cor local nesse excerto, como fidelidade, observação, visão ampla, imaginação, tempo e espaço, irão delimitá-la durante o século XIX. O emprego do dispositivo, independentemente do tipo discursivo, evoca, portanto, essas potencialidades e características. Mesmo na escrita da história seria possível identificá-las. Tais elementos se agregam na elaboração de uma, sugere Fluckiger, "rede de imagens que são projetadas sobre o passado ou o estrangeiro e que são objeto de um consenso [...]”.

No entanto, retornemos às potencialidades da cor local. $\mathrm{O}$ dispositivo, como dito, se articula nas primeiras décadas do século XIX. Qual é, portanto, o grande mote que auxilia na sua compreensão? Por que ele carrega propriedades como a viagem temporal, a observação exata e a fidelidade representacional? Qual, enfim, é o objeto principal da cor local? Não há dúvida de que o recurso tem a nação como seu principal sujeito. É ela ainda que irá, como tentarei apresentar, conformar a literatura que adquire novas acepções nesse período. Fluckiger, então, esclarece a relação entre a cor local e a questão nacional: "a noção de "cor local" se articula sobre essa problemática do nacionalismo, na medida em que ela postula a possibilidade de uma representação: de entidade abstrata que era, a nação pode ser apreendida de modo sensível e concreto" ${ }^{8}$

A citação é fundamental para este artigo. No momento em que a nação se torna tema e objeto fundamental para os pensadores do século XIX, é necessário desenvolver formas e mecanismos que permitam apreendê-la e representá-la. A nação passa a ser identificada como o objetivo do progresso social e por isso se torna um princípio regulador, por exemplo, para a literatura e para a história. É necessário, então, também definir sua língua característica e a constituição de sua população, além de apontar seus mitos e heróis. Com isso, a nacionalidade, paulatinamente, abandona a abstração que lhe era característica e adquire maior fundamentação e concretude. Dois aspectos fundamentais para isso são justamente a temporalização dessa nação, ou seja, a construção de um passado e uma cronologia específica e, ainda, a constituição de um espaço capaz de identificar os limites e o território desse corpo nacional. Tempo e espaço, portanto, são dois vetores fundamentais para a elaboração

\footnotetext{
${ }^{6}$ Ibid., p. 34. "L'idéal qui sous-tend la notion de "couleur locale", en effet, est celui de la "vie" ou de la "realité" fidèlement reproduite. L’artiste s'attribue dans ce sens des dons d'observateur presque illimités, puisqu'il peut "voir" la "realité" dans toute as multiplicité, traverser les frontières — géographiques et mentales - et même, par le pouvoir magique de son imagination, voyager dans le temps".

${ }^{7}$ Ibid., p. 23-24. "un réseau d'images qui sont projetées sur le passé ou l'étranger et qui font l'objet d'un consensus [...]”.

${ }^{8}$ Ibid., p. 46. "la notion de "couleur locale" vient s'articuler sur cette problématique du nationalisme, dans la mesure où elle postule la possibilité même d'une représentation: d'entité abstraite qu'elle était, la nation peut être appréhendée de façon sensible ou concrète".
} 
da homogeneidade nacional. Ambos, aliás, participam da concepção da cor local corrente durante este período. Recupero-a, pois.

Jan Kamerbeek, em obra de referência sobre termos literários, estabelece que a noção romântica de cor local remete a três elementos: localidade, temporalidade e centralidade. 9 Além disso, a definiçâo fornecida ainda compreende uma rápida historicização do termo como forma de tratar do processo de enriquecimento semântico que caracteriza esta acepção. Assim, o sentido romântico marca a intersecção de duas tradições: a primeira é a noção de genius saeculi que remete ao espírito do século ou Zeitgeist, corrente por volta de 1600. A centralidade, depois incorporada ao dispositivo, deriva justamente daí, pois é fundamental nessa noção de espírito. Por outro lado, há também, no século XIX, a tradição artística, de origem teatral e pictural que remete à categoria de costume. Esse termo, de origem italiana, possui, no princípio do século XIX, duas conotaçôes. A primeira, datada do século XVII, faz referência à verdade da reprodução, por poetas, escritores e artistas, dos usos e costumes. A outra acepção, por sua vez, surge a partir da segunda metade do século XVIII, e evoca a "maneira de se vestir". Estas seriam, pois, as anexaçôes que concorreram para o estabelecimento da cor local na sua concepçáo romântica. ${ }^{10}$

É importante caracterizar a acepçáo acima exposta como "romântica" na medida em que a cor local ainda é um dispositivo válido hoje em dia. Entretanto, sua caracterização contemporânea é bastante diferente, menos complexa e abrangente. Sua definição atual parece ter perdido as dimensôes temporal e central da acepção oitocentista. No Dictionary of Literary Terms, obra da década de 1960, o dispositivo significa uma escrita que explora o discurso, a vestimenta, os maneirismos, os hábitos de pensamento e a topografia peculiares a uma regiáo. ${ }^{11}$ Assim, a partir do reconhecimento da instabilidade conceitual da cor local e considerando as elucubraçóes de Staël e as abordagens de Fluckiger e Kamerbeek mencionadas, é possível apenas sugerir uma definição provisória e sujeita a retificaçôes: a cor local é um dispositivo narrativo derivado dos debates acerca da pintura e que tem por objetivo destacar aquilo que identifica e caracteriza um tempo e um espaço específicos para um país ou uma nação.

Um aspecto que gostaria de ressaltar - e este é um dos principais objetivos desse artigo - é que sua origem pictural tende a estimular e desenvolver o aspecto visual da narrativa. Em outras palavras, oriunda da pintura, a cor local jamais abandona sua dimensão visualizante. A fim de circunscrevê-la, creio que o dispositivo enseja e participa do que poderia ser denominado de "retórica pictórica", isto é, um extenso, mas limitado, conjunto de expressóes que remetem ou participam do vocabulário pictórico, tais como colorido, pintura, desenho, debuxo, quadro, imagem, entre outras. Esses vocábulos, recorrentes nos textos a serem men-

${ }^{9}$ KAMERBEEK, Jan. Couleur. In: ESCARPIT, Robert. Dictionnaire international des termes littéraires. Berne: A. Francke, 1986, p. 399.

${ }^{10}$ Ibid., p. 399-400.

${ }^{11}$ Dictionary of literary terms. Toronto: Coles Publishing Company, c. 1963, p. 67. 
cionados, indicam, pois, a presença da cor local. A composição deste léxico pictural foi a maneira encontrada para evitar uma apreensão demasiado subjetiva do objeto. ${ }^{12}$ Dessa forma, é possível construir um determinado idioma comum que permite a verificação do emprego do dispositivo narrativo.

Em meados do século XIX, portanto, justamente no processo de constituição da nacionalidade, era imperativo apreender o espaço da nação e, de forma simultânea, registrar o tempo que se instabilizava a partir de eventos capitais como a migraçáo da corte portuguesa e o próprio processo de independência política. As duas dimensôes, ademais, embora expressem propriedades diferentes, muitas vezes se mesclam na representação. Torna-se, então, impossível dissociá-las. Os exemplos fornecidos a seguir, sugiro, carregam essa dupla inscrição. Consoante Koselleck, esse vínculo entre tempo e espaço se efetiva desde o século XVIII. ${ }^{13}$ E, em relação ao dispositivo narrativo, Fluckiger assevera que tempo e espaço podem se integrar. ${ }^{14}$ Desta forma, a naçáo pode ser concebida como tema e motivo da cor local. E o dispositivo pode ser visto como um instrumento capaz de apreender a temporalidade e a espacialidade que conferem, como dito, concretude ao corpo nacional.

\section{Cor local e temporalidade da nação}

\section{A cor local como registro do tempo nacional}

No momento que se organiza uma escrita da história nacional, é fundamental estabelecer seus limites cronológicos e períodos específicos. Tentarei demonstrar que a cor local é também importante nesse processo. Para isso, é importante retomar algumas das prescriçôes mais conhecidas em relação ao dispositivo. Como lembra Vladimir Kapor, as formulaçôes de Victor Hugo e Benjamin Constant podem ser caracterizadas como as "artes poéticas" da "escola romântica". ${ }^{15}$ No entanto, enquanto Hugo prioriza a questão da centralidade, fundamental para a escrita da literatura, mas pouco importante para a historiografia, Constant sintetiza o uso da cor local na escrita da história. Além disso, na sua prescrição, tal como se perceberá na formulação de Madame de Staël, já é possível notar também, direcionado à história, a presença de um topos duplo que regulava sua utilização: uma cor local positiva e

\footnotetext{
${ }^{12}$ A elaboração dessa linguagem relativa à cor local se assemelha à seleção, empreendida por Franco Moretti, de palavras-chave que, em comunhão com uma prosa específica, permitem identificar as peculiaridades da cultura burguesa na linguagem literária dos séculos XVIII e XIX. MORETTI, F. The bourgeois: between literature and history. Londres; Nova York: Verso, 2013, p. 18-19.

${ }^{13}$ KOSELLECK, Reinhart. Los estratos del tiempo: estudios sobre la historia. Barcelona: Paidós, 2000, p. 94.

${ }^{14}$ FLUCKIGER, C. L'histoire entre art et science, op. cit., p. 41.

${ }^{15}$ KAPOR, Vladimir. Exotisme et couleur locale - essai d'une analyse constrastive des champs sémantiques respectifs. Conference Paper. Proceedings, France and the Exotic, University of Birmingham, UK, 2003, p. 3.
} 
presente na produção, e, seu oposto, uma cor local negativa e ausente. ${ }^{16}$ A presença ou ausência do dispositivo legitima ou desautoriza a composição textual, seja ela de caráter literário ou histórico.

É possível fornecer dois exemplos dessa perspectiva que combina, simultaneamente, demanda e crítica. No seu amplo panorama acerca da Alemanha, por exemplo, Madame de Staël vale-se amiúde da "retórica pictórica” para criticar as composiçóes literárias alemãs. ${ }^{17} \mathrm{O}$ aspecto significativo, contudo, é que critérios como a cor local também passam a determinar a escrita da história. Staël dedica então um capítulo para tratar dos historiadores alemães. A autora francesa identifica três classes principais de tipos de escritos históricos publicados na Alemanha: a história erudita (composta por nomes como Mascou, Schoepflin, Schloezer, Gatterer, Schmidt), a história filosófica (representada por Schiller) e — o gênero que mais interessa para este artigo - a história clássica (que possui Müller como principal expoente).

De acordo com Staël, Johannes von Müller é o mais sábio dos historiadores, aquele que "foi realmente um poeta na maneira de pintar os eventos e os homens". ${ }^{18}$ A estudiosa francesa ainda menciona "a verdade viva de seus quadros" e sublinha a "escrupulosa fidelidade" de sua representação. ${ }^{19}$ Desta forma, sua pintura dos eventos da Confederação Helvética é elogiada. Suíço, o historiador foi capaz de pintar com maior precisão os acontecimentos que antecederam a constituição da Suíça moderna. Até porque "Seria equivocado se fazer historiador de um país que não se tivesse visto por si mesmo. Os sítios, os lugares, a natureza, são como o fundo do quadro [...]". ${ }^{20}$ Ademais, Müller é exaltado devido ao emprego de sua linguagem, capaz de comover a alma. E, por fim, a escritora destaca a cor local presente na sua obra: "É sobretudo à cor de seu estilo que Müller deve seu poder sobre a imaginação; as palavras antigas das quais ele se serve, tão a propósito, têm um ar de lealdade germânica que inspira confiança". ${ }^{21}$

Apreciaçôes como essas permitem perceber como o dispositivo narrativo adquire um duplo efeito na escrita da história. Torna-se necessário incorporar seu vocabulário (composto pela "retórica pictórica") na medida em que ele designa, por um lado, uma representação fiel do passado, enquanto, por outro, possibilita o estímulo da imaginação daquele que lê o relato. Desta forma, é possível afirmar que autópsia e imaginação estão conectadas ao em-

\footnotetext{
${ }^{16}$ Antonio Candido aborda a mesma questáo na literatura nacional: a presença do pitoresco representa o índice de validade do texto. Cf. CANDIDO, A. Literatura e sociedade. Rio de Janeiro: Ouro sobre azul, 2006, p. 161.

${ }^{17}$ Staël emprega expressôes como couleur historique, couleur poétique e couleur des siècles. STAËL, Madame de. De L'Allemagne. In: Oeuvres complètes de Mme. la baronne de Staël. Paris: L'Imprimerie de Plassan, tomo 11,1820 , p. 17, 20 e 23.

${ }^{18}$ Ibid., p. 116. "qui a été vraiment poète dans sa manière de peindre les événemens et les hommes".

${ }^{19}$ Ibid., p. 118.

${ }^{20}$ Ibid., p. 119. "On auroit tort de se faire l'historien d'un pays qu'on n'auroit pas vu soi-même. Les sites, les lieux, la nature, sont comme le fond du tableau [...]".

${ }^{21}$ Ibid., p. 122. "C'est surtout à la couleur de son style que Müller doit sa puissance sur l'imagination; les mots anciens dont il se sert si à propos ont un air de loyauté germanique qui inspire de la confiance".
} 
prego da cor local. Outra ilustração da demanda pela cor local deriva da pena de Benjamin Constant. Sua apreciação é fundamental porque, justamente, ilustra a necessidade do uso da cor local na historiografia francesa. Em 1829, ao comentar o emprego do dispositivo na escrita literária, o crítico alarga a análise e inclui a produção da história:

Se eu quisesse sair do meu assunto, e aplicasse esse preceito à história, eu diria que a ausência de cor local pode provocar uma impressão penosa, quando lemos Hume tão vaidoso, Robertson tão esforçado, Gibbon tão amplo na sua erudição e tão monótono nas suas antíteses. Esses historiadores, e outros mais recentes, não possuem como seu mestre Voltaire, a cor nem dos tempos, nem dos lugares que eles descrevem. Os eventos pertencem às épocas passadas, os atores são da nossa idade. Graças ao céu, o Sr. Guizot, de Barante e Thierry fundaram uma outra escola. $^{22}$

A dupla dimensão, tempo e espaço, está, como se percebe, implícita na formulação. Em busca de uma maior precisão, Constant elabora duas variações para a cor local e menciona a cor dos tempos e a cor dos lugares. São duas faculdades fundamentais para a escrita da história. No entanto, acredito que o exemplo fornecido tende a destacar a questão temporal, tanto que o escritor menciona épocas e idade. O emprego da cor local, assim, evitaria um equívoco fatal dos historiadores: o anacronismo. Para isso concorria não só o emprego de fontes, expressóes da época abordada, mas também uma crença ilusionista na capacidade da transposição temporal. ${ }^{23}$ A delimitação das épocas e períodos diferentes é uma maneira de organizar a escrita da história. Afinal, para Prosper de Barante, recorda Fluckiger, cada período é dotado de uma coerência própria e específica. ${ }^{24}$ Essa coerência requer uma determinada forma de apreensão que incorpora, na medida do possível, os instrumentos criados por esse próprio momento.

\footnotetext{
${ }^{22}$ CONSTANT, Benjamin. "Réflexions sur la tragédie [...]". Revue de Paris, Bruxelles, t. 7, 1829, p. 143. "Si je voulais sortir de mon sujet, j'appliquerais ce précepte à l'histoire; je dirais que le défaut de couleur locale nous poursuit d'une impression pénible, quand nous lisons ce Hume si vanté, ce Robertson si laborieux, ce Gibbon si varié dans sons erudition et si monotone dans ses antithèses. Ces historiens, et d'autres plus récens, n’ont, comme leur maître Voltaire, la couleur ni des temps ni des lieux qu'ils décrivent. Les événemes appartiennent aus âges écoulés; les acteurs son de notre âge. Grâce au ciel, MM. Guizot, de Barante et Thierry ont fondé une autre école".

${ }^{23} \mathrm{E}$ a cor local não é a única forma de efetuar esta transposição. Em seu estudo sobre os dioramas, Valdei Araujo argumenta que o escopo do mecanismo era seduzir o olhar do espectador e provocar a sensação de viagem no tempo e espaço. ARAUJO, Valdei. Observando a observação: sobre a descoberta do clima histórico e a emergência do cronótopo historicista. In: CARVALHO, José Murilo; CAMPOS, Adriana Pereira (Orgs.). Perspectivas da cidadania no Brasil Império. Civilização Brasileira: Rio de Janeiro, 2009, p. 289. Assim, dispositivos ópticos, como o diorama, e dispositivos narrativos, como a cor local, convergem, a despeito dos meios empregados.

${ }^{24}$ FLUCKIGER, C. L'histoire entre art et science, op. cit., p. 6.
} 
A coerência, contudo, náo se refere somente à abordagem do historiador que escreve sobre o passado. A cor local aqui também é uma forma de apreender determinado espaço temporal na sua integralidade. Fluckiger esclarece que o dispositivo pode ser compreendido como a "fisionomia", mas ainda como o "caráter" de uma "época", e apreende também tanto seu aspecto físico quanto seu "espírito". Seja para o historiador, seja para o poeta, a cor local fornece, portanto, um critério de seleção de detalhes característicos. Por isso, um século e uma nação podem ser vistos, entấo, como estruturas unificadas, únicas, dotadas de certo caráter. ${ }^{25} \mathrm{E}$ o caráter nacional, por sua vez, como se esboça? Quais são as épocas que constituem a história do império?

\section{As temporalidades da nação e os princípios sem fim}

Valdei de Araujo demonstrou que a temporalidade no Brasil, ou melhor, a forma de experienciá-la, sofreu profundas modificaçóes no início do século XIX. A partir de eventos capitais, como a independência, é possível perceber como o horizonte de expectativas e o espaço de experiências dos indivíduos que vivenciaram o momento se alteram. Essas desordens repercutem diretamente na forma de se sentir o tempo e o momento no qual se vive. Assim, o que se percebe é um processo de reformulação e reorientação conceitual. ${ }^{26}$ Inúmeros conceitos e categorias assumem acepções diferentes, como é o caso da história, e, além disso, novos conceitos são criados a fim de descrever e apreender a realidade coetânea.

A literatura é parte dessa reformulação conceitual. A experiência moderna altera seu significado anterior - embora seja possível afirmar que elementos da noção antiga permaneceram inerentes ao novo conceito. A partir de então, as produçóes literárias se veem vinculadas a dois pressupostos: elas são concebidas como a expressão de um determinado tempo e lugar específicos e, além disso, permanecem atreladas a um conjunto de obras, procedimentos e referências antigas herdadas da concepção anterior. Ora, em relaçáo ao primeiro aspecto, se a literatura deve exprimir um tempo-espaço particulares e, nesse período, a nação assume a posição central da reflexão, é possível esperar que a produção literária expresse o caráter dessa nacionalidade específica. Justamente por registrar a temporalidade no momento em que ela se instabiliza, é válido conceber a literatura como, de acordo com Araujo, uma espécie de cápsula do tempo. ${ }^{27}$

Além da reformulação de conceitos já existentes, é importante também recordar que as modificaçôes se efetuam por meio da introdução de novas categorias, acepçôes e metáforas aos conceitos. Acredito que a noção de cor local é uma dessas novas incorporaçóes que se

\footnotetext{
${ }^{25}$ Ibid., p. 35.

${ }^{26}$ ARAUJO, Valdei. A experiência do tempo: conceitos e narrativas na formação nacional brasileira (18131845). São Paulo: Hucitec, 2008, p. 65.

${ }^{27}$ Ibid., p. 120.
} 
associam à literatura e à história. De acordo com o estudo de Malakis, é no final do século XVIII que o vocabulário pictórico, no contexto francês, é incorporado pela crítica literária. ${ }^{28}$ No entanto, é somente no início do século seguinte que a cor local adquire uma acepção mais estável e uniforme, como se percebe a partir das reflexôes sobre o dispositivo mencionadas, datadas das primeiras décadas do século XIX.

A escrita da história e, mais do que isso, a cultura histórica se encontravam, então, diante do desafio imposto por um tempo instável que ameaçava também o porvir. Mesmo o projeto civilizatório em curso via-se, desta forma, atingido. Diante, portanto, desse receio generalizado, torna-se necessário registrar o tempo atual. Período esse que era concebido como o ponto de chegada de um longo processo de amadurecimento e evoluçáo, porque marcava a independência política e o abandono da condição colonial. Desta forma, também esse período é encapsulado, ou seja, registrado e monumentalizado, como forma de apaziguar a indefinição produzida por um futuro em aberto. Assim, o anseio de superação, ou a própria instabilidade temporal desencadeada, requeria controle e organização. Cabia, portanto, aos historiadores e ao IHGB propor soluçôes e alternativas. Koselleck aponta: "A exatidão cronológica na classificação de todos os elementos que constituem os eventos pertence por isso ao postulado metodológico da narrativa histórica." ${ }^{29}$

Destarte, já na sessão inicial do IHGB, Januário da Cunha Barbosa, em seu discurso de abertura, esboça uma circunscrição do tempo ainda bastante genérica. A história estaria dividida em dois grandes períodos: antigo e moderno. Cada uma dessas fases, por sua vez, deveria ainda encerrar outros ramos e épocas. ${ }^{30} \mathrm{O}$ aspecto significativo é que o primeiro secretário perpétuo da agremiação sugere possíveis princípios para a história do Brasil a partir do período moderno. Três proposições seriam possíveis para a história do império: ação religiosa (missionários), ação guerreira (colonizadores) e situação natural (riquezas e prodigalidade). Dois marcos temporais, portanto, são humanos, enquanto o outro é natural. É possível constatar já a importância que a natureza assume para a história do Brasil. Concebida como uma possibilidade de princípio, o historiador, se adotasse tal alternativa, deveria encetar a sua história destacando a composição natural da nação, ou seja, descrevendo a paisagem que a compóe. Desta forma, se percebe aqui a associação, já apontada, entre o tempo e o espaço. Trata-se de conceber uma dimensão como inerente à outra e, consequentemente, a própria paisagem passa a ser historicizada, na medida em que atua como um marco temporal.

Essa relação tempo-espaço permite evocar inclusive duas concepçóes de espaço que são descritas por Koselleck. De acordo com o historiador alemão, há uma noção de espaço que pode ser compreendida como meta-histórica, na medida em que constitui as condições de

\footnotetext{
${ }^{28}$ MALAKIS, Emile. The First Use of Couleur Locale in French Literary Criticism. Modern Language Notes, Baltimore, v. 60, n. 2, 1945, feb., p. 98.

${ }^{29}$ KOSELLECK, Reinhart. Futuro passado. Contribuição à semântica dos tempos históricos. Rio de Janeiro: Contraponto/Editora PUC-Rio, 2006, p. 134.

${ }^{30}$ CUNHA BARBOSA, Januário da. Discurso. Revista do IHGB, Rio de Janeiro, t. 1, 1908 [1839], p. 10.
} 
possibilidade da história e da ação humana. Essa espacialidade é composta pelas formaçôes geológicas, rios, matas, climas e alteraçôes de caráter estritamente naturais. ${ }^{31}$ Seria a esta noção que Cunha Barbosa se refere como possível início da história do Brasil. No entanto, há ainda outro sentido de espaço. Nesse, o homem é o vetor principal. É ele quem se introduz no espaço, o habita, trabalha e o configura. ${ }^{32}$ Justamente as duas outras possibilidades aventadas por Cunha Barbosa: a ação religiosa e guerreira como princípio temporal de um território que começa a se constituir.

A despeito dessas sugestôes, o cônego brasileiro esboça, ainda em 1838, um programa que deveria ser responsável por determinar as épocas da história do Brasil. Após algumas discussões, a questão é encerrada sem uma resolução consensual. ${ }^{33}$ Alguns anos após o programa de Cunha Barbosa, o bávaro Karl von Martius envia sua dissertação argumentando como a história do Brasil deveria ser escrita. O naturalista não investe na questão sobre as diferentes épocas, mas ratifica a necessidade de empreender divisóes cronológicas para a escrita da história. E acrescenta que essas divisóes temporais precisam estar em conformidade com as diferentes regiốes da nação. ${ }^{34} \mathrm{O}$ aspecto significativo de sua proposição é a imbricação, mais uma vez, entre tempo e espaço. Assim, a história deveria ser escrita a partir de divisóes cronológicas, contudo, essas repartiçóes devem ainda contemplar as divisas espaciais, isto é, os limites regionais. Logo, creio ser legítimo afirmar que não existe um tempo determinado sem um espaço específico relacionado. Ora, a cor local parece reforçar essa ideia. Por meio do dispositivo, entâo, tempo e espaço se conectam. E isso corrobora seu uso em um momento no qual ambos os vetores eram importantes para a elaboração da nação.

Todas essas propostas e indefiniçôes, além dos diferentes princípios estabelecidos para a escrita da história do Brasil, demonstram a complexidade da questão temporal neste momento. Era imperativo estabelecer um início para a escrita, contudo, a temática não deixava de impor questionamentos aos historiadores e seus pares: incluir o período indígena? Considerar a chegada dos europeus? Destacar a natureza? Abordar o tempo presente? As dúvidas, contudo, não foram capazes de impedir a concretização da obra historiográfica, como se percebe a partir da produçáo de Francisco Adolfo de Varnhagen que busca, a seu modo, responder a esses questionamentos.

\footnotetext{
${ }^{31}$ KOSELLECK, Reinhart. Los estratos del tiempo, op. cit., p. 99.

${ }^{32}$ Ibid., p. 100.

${ }^{33}$ A única proposta publicada na Revista do IHGB foi a de autoria de Raimundo José da Cunha Matos que, contudo, só apareceu na Revista na década de 1860. Para o aprofundamento da questão: ARAUJO, Valdei. A experiência do tempo, op. cit., p. 171-173.

${ }^{34}$ MARTIUS, Karl Friederich Phillipe von. Como se deve escrever a historia do Brazil. Revista do IHGB, Rio de Janeiro, t. 6, 1973 [1844], p. 400.
} 


\section{$O(s)$ tempo(s) da nação segundo Varnhagen}

As iniciativas empreendidas por Varnhagen demonstram não só a relevância das demarcaçôes para a estrutura da escrita da história e da economia da obra, mas também em relação ao conhecimento pragmático concernente ao passado da nação. Após algumas especulaçôes e proposições, Varnhagen, ao publicar a sua Historia geral do Brazil, em 1854, sugere também uma ordenação temporal. O historiador estabelece como início da história o descobrimento da América Central. A descrição do espaço do Brasil e a abordagem sobre os indígenas são inseridos, respectivamente, nas seçôes VII e VIII da obra. Essa demarcação, contudo, é rechaçada por Armand d'Avezac. $\mathrm{Na}$ análise que faz do texto, o geógrafo francês critica essa organização e, por extensão, afirma que Varnhagen teria adotado o ponto de vista português..$^{35} \mathrm{~A}$ querela é conhecida. ${ }^{36} \mathrm{O}$ historiador brasileiro replica, mas na segunda edição da publicação, em 1877, altera a ordem dos capítulos e, de certa forma, o princípio da história, ao realocar essas seçôes para o início da obra.

A temporalização incorpora, evidentemente, a discriminação e identificação de períodos diferentes, como o passado, o presente e o futuro. Ao reconhecimento dessas esferas específicas, segue-se a valoração dos períodos. Para Varnhagen, então, a pesquisa sobre o passado tem objetivos pragmáticos e inclui a própria governabilidade do império. $\mathrm{O}$ fragmento demonstra a posição do historiador:

É assim que os estudos acerca do passado de uma nação nunca são inuteis para o governo della, como muitos politicos improvisados querem desdenhosamente inculcar, para não dar importancia ao que não aprenderam, e que alias devera $[s i c]$ nas universidades ensinar-se com o direito administrativo, até porque as glorias communs da mesma historia suscitam mais sympathias mutuas e por conseguinte maior integridade no presente. ${ }^{37}$

A história, portanto, fornece meios e revela sua importância para promover uma maior integridade nacional no presente. $\mathrm{O}$ passado homogêneo e repleto de feitos significativos desperta, contemporaneamente, a simpatia dos habitantes da nação. O conhecimento do tempo precedente serve a um duplo propósito, pois: integração nacional e recurso aos dirigentes. Por fim, Varnhagen emprega ainda uma analogia que, uma vez mais, pode ser concebida como demarcando a conexão entre a temporalidade e a espacialidade: "Para edificar solidamente necessita o architecto conhecer o terreno; se já alguma vez desabou, se ha nelle

\footnotetext{
${ }^{35}$ D’AVEZAC, Armand. Considérations géographiques sur l'Histoire du Brésil. Examen critique d'une nouvelle Histoire Générale du Brésil. Paris: Imprimerie de L. Martinet, 1857, p. 9-10.

${ }^{36}$ Para um aprofundamento da questão: CEZAR, Temístocles. Anciens, Modernes et Sauvages, et l'écriture de l'histoire au Brésil au XIX siècle. Le cas de l'origine des Tupis. Anabases, n. 8, 2008, p. 50.

${ }^{37}$ VARNHAGEN, Francisco Adolfo de. Historia geral do Brazil [...]. Rio de Janeiro: E. H. Laemmert, 1857, p. 315-316.
} 
ruinas, cujas pedras e alicerces possam aproveitar-se; se tem matos que se devem cortar, utilizando-se as madeiras, etc." 38

A citação revela, enfim, a relevância do conhecimento e pesquisa do pretérito para a ação no presente e no futuro. Como ocorre, contudo, a determinação das épocas anteriores desse terreno que é necessário conhecer? Varnhagen multiplica as determinações que identificam e caracterizam justamente o pretérito. Ao longo dos dois tomos da Historia geral do Brazil, o historiador vale-se de inúmeras expressôes para apreender a temporalidade prévia. Assim, para apontar o passado, o historiador emprega construçôes como "naquelles tempos", "tempos immemoriaes", "tempos primitivos", "tempos antigos", "antigos tempos", "aquelles tempos", "tenebrosos tempos", "tempos bárbaros", "tempos heroicos”, "n’outros tempos”, "tempos remotos", "nesses tempos de superstição", "tempos da primitiva colonisação" e "tempos anteriores". Como se percebe, essas demarcaçôes temporais, por vezes acompanhadas de definiçóes que atribuem um juízo ao período, sinalizam para momentos diversos. O que as aproxima, todavia, é o fato de que elas apontam para épocas diferentes, ou seja, para terrenos que não são mais os "nossos". De modo oposto, o período atual, que participa ou está mais próximo do presente, recebe caracterização diversa. Para se referir ao seu tempo, Varnhagen emprega, em profusão, o vocábulo "hoje" e, em menor escala, "nossos dias" e "nossos tempos". Desta forma, o historiador delimita as épocas que irão compor a obra e que permitem a organização temporal.

Esse procedimento é inerente ao ofício histórico. Cada período requer uma caracterização e denominaçôes específicas, na medida em que contém uma fisionomia própria e, portanto, é individualizado em relação aos demais. Entretanto, o aspecto interessante dessa temporalização é que ela permite também a transposição entre momentos diferentes. Essas "viagens temporais", propriedade da cor local, objetivam estabelecer comparaçóes e determinar as diferenças específicas entre cada período. No caso de Varnhagen, o historiador reafirma ao leitor que "aqueles tempos" já não são mais os "nossos" ${ }^{39}$ É imperativo, pois, esboçar a diferença entre ambos. E, da mesma forma que era necessário conhecer os limites temporais, o espaço também precisava ser explorado e discutido.

\footnotetext{
${ }^{38}$ Ibid., p. 316.

${ }^{39}$ Flora Süssekind, aliás, identifica esse mesmo exercício na escrita de José de Alencar: "Lembre-se, nesse sentido, o número de vezes em que se interpola alguma digressão opondo um 'hoje' a um 'naquele tempo' em As minas de prata”. SÜSSEKIND, F. O Brasil não é longe daqui: o narrador, a viagem. São Paulo: Companhia das Letras, 1990, p. 200.
} 


\section{Cor local e espacialidade da nação}

\section{A cor local como apreensão do espaço nacional}

Com o intuito de abordar a dimensão espacial da cor local, se faz necessário retomar alguns elementos implícitos ao dispositivo e sua análise. Ela é oriunda do campo pictórico e por isso retém uma dimensão visual muito destacada. Além disso, quando a expressão é empregada em discursos diferentes aos quais se originou - as elucubraçôes sobre a pintura — ela adquire a condição de metáfora ${ }^{40}$ Acrescento, por fim, que a cor local é utilizada de modo mais acentuado nas parcelas descritivas dos textos. Isso porque esses enunciados, ao comportarem disputas de competências, constituem-se nas áreas ideais para o emprego de recursos narrativos variados, como as metonímias e, evidentemente, as metáforas. ${ }^{41}$

É a partir, portanto, da combinação desses pressupostos que destacam a visualidade da cor local que é possível concebê-la como um instrumento de apreensão do espaço da nação. Afinal, as descriçôes da natureza tendem a instituir quadros da paisagem que conformam o território e, desta forma, fornecem a fisionomia nacional. Novamente as discussões acerca da literatura nesse período auxiliam nesta reflexão. De acordo com Flora Süssekind, o louvor ou a descrição da natureza, o paisagismo, enfim, perpassa a constituição do narrador de ficção no Brasil oitocentista. ${ }^{42}$ Tanto sua primeira figuração (décadas de 1830 e1840), quanto o segundo momento (1850-1860) se baseiam no paisagismo, seja ele naturalístico, seja ele histórico. Acerca do primeiro estágio, Süssekind afirma: "Na novela de fins da década de 30, a questão é mapear o território, listar e esboçar paisagens. O que está em primeiro plano é a delimitação da paisagem nacional, é a descrição do território, são notas informativas sobre ele."³3

Nesse processo, o território também passa a ser historicizado. Retomemos Koselleck. O historiador assevera que o espaço funciona de forma meta-histórica e, simultaneamente, pode ser historicizado, porque é passível de ser modificado de forma social, econômica e política ${ }^{44}$ Como entáo ocorre a apreensáo do espaço nacional? Novamente a ideia de cápsula do tempo, empregada por Araujo, é válida aqui. A cápsula não diz respeito apenas ao tempo, mas também formata a memória de um local determinado. Ainda nesse processo de definição nacional, serão importantes as análises de viajantes e cronistas estrangeiros, como Ferdinand Denis, que tendem a destacar o caráter específico do império. ${ }^{45} \mathrm{O}$ escopo é salientar a cor característica da nação, ou seja, sua cor local.

\footnotetext{
${ }^{40}$ KAPOR, Vladimir. Local colour, op. cit., p. 7.

${ }^{41}$ HAMON, Philippe. Du Descriptif. Paris: Hachette Livre, 1993, p. 43.

42 SÜSSEKIND, Flora. O Brasil nâo é longe daqui, op. cit., p. 187.

${ }^{43}$ Ibid., p. 158.

${ }^{44}$ KOSELLECK, Reinhart. Los estratos del tiempo, op. cit., p. 97.

${ }^{45}$ Ferdinand Denis é o elo, neste período, entre literatos brasileiros e europeus. ROUANET, Maria Helena. Eternamente em berço esplêndido: a fundação da literatura nacional. São Paulo: Siciliano, 1991, p. 152.
} 
O mapeamento da nação não estava restrito, contudo, aos literatos. É possível pensar, inclusive, que o próprio IHGB participava desse projeto. Se a ênfase da instituição recairá, ulteriormente, sobretudo na dimensão historiográfica, é imperativo ressaltar que a academia é fundada considerando igualmente o saber geográfico. A comunhão desses conhecimentos se concretiza, sobretudo, em um gênero específico de apreensão do espaço: as corografias. ${ }^{46}$ Os ofícios histórico e geográfico concorriam, informa Temístocles Cezar, para os esforços de construção de uma unidade nacional, ao mesmo tempo que essas práticas se legitimavam. ${ }^{47}$ E, nesse empreendimento, a geografia desempenhou um papel importante e equivalente ao da história, ao menos até meados do século XIX. De acordo com Lilian Carlos: "Quando Cunha Mattos e Cunha Barbosa propuseram a criação de uma instituição histórica e geográfica, foi porque eles pretendiam desenvolver dois ramos do conhecimento que tinham, cada um, seu objeto, — ainda que devessem estar em constante relação" ${ }^{48}$ Ambos os saberes concorriam, portanto, juntamente com a literatura, para conformar a paisagem do Estado imperial.

O aspecto fundamental a ser destacado é que o conhecimento geográfico desvela o território do império, ou seja, torna-o passível de ser visto e reconhecido. Ora, salientei anteriormente que a cor local, devido à sua origem e à sua condição metafórica, carrega uma dimensão imagética bastante evidente. Assim, se o escopo é revelar o espaço para os brasileiros, a cor local pode ser vista como um subsídio fundamental. Desta forma, por um lado, o espaço é concebido como fundamental para a constituição da nação, na medida em que é a partir dele que o Estado se organiza. Por outro, como mencionado, a escrita da história participa desse processo de constituição do território nacional. Portanto, é possível esperar que, de alguma forma, o espaço seja inserido nas obras historiográficas do período. Como, no entanto, isso é feito? Como a escrita da história incorpora o território da nação? Essa inserção, acredito, ocorre a partir das descriçóes das paisagens redigidas pelos historiadores do período. Afinal, os enunciados descritivos não só estão presentes nas obras de historiadores, como também, tentarei sugerir, são partes importantes da construção de seus argumentos.

A questâo acima, contudo, pode receber uma resposta alternativa que diz respeito a outro nível de análise. A paisagem é incorporada na obra historiográfica como uma estrutura. Cabe aqui retomar, pois, a distinção comentada por Koselleck entre evento e estrutura. Ambos se diferenciam na medida em que, enquanto o primeiro é extraído da infinidade dos acontecimentos, a segunda evoca duraçóes de tempo mais longas e não necessariamente su-

\footnotetext{
${ }^{46}$ PEIXOTO, Renato. A máscara da medusa: a construção do espaço nacional brasileiro através das corografias e da cartografia no século XIX. Tese (doutorado em História). Rio de Janeiro: UFRJ, 2005, p. 126. ${ }^{47}$ CEZAR, Temístocles. A geografia servia, antes de tudo, para unificar o império. Escrita da história e saber geográfico no Brasil oitocentista. Ágora, Santa Cruz do Sul, v. 11, n. 1, 2005, jan./jun., p. 83.

${ }_{48}$ CARLOS, Lilian. Uma relação a dois: a história e a geografia nos primeiros anos do Instituto Histórico e Geográfico Brasileiro. Dissertação de Mestrado em História. São Leopoldo: Unisinos, 2008, p. 29.
} 
cessivas. ${ }^{49}$ Essa distinção enseja uma diferença formal. Assim, camadas alternativas de tempo requerem distintas aproximaçóes metodológicas, ou seja, meios diversos de comunicação de conteúdo na escrita da história. Ora, os eventos recebem, pois, um tratamento narrativo; já as estruturas, por sua vez, demandam um desenvolvimento descritivo. ${ }^{50}$

A longa duração ou a estrutura podem ser expressas justamente pela paisagem, pela natureza. O historiador alemão reconhece essa possibilidade. ${ }^{51}$ Além disso, evocando a diferença entre espaços, instituída também por Koselleck, recorde-se que uma de suas manifestaçôes atuava como em elemento meta-histórico. A estrutura também carrega essa abrangência e é a partir daí que há o encadeamento com o evento: "estruturas mais ou menos duradouras, mas de todo modo de longo prazo, são condiçôes de possibilidades para os eventos". ${ }^{52}$ Em síntese, a incorporação da paisagem responde tanto a uma necessidade cognitiva (o espaço permite uma compreensão mais apropriada da história e o seu reconhecimento), quanto discursiva (a estrutura incorpora os eventos). ${ }^{53}$

Varnhagen permite ilustrar esse argumento em seu duplo nível. A ideia do reconhecimento a partir do exercício descritivo mais uma vez se impóe. É possível percebê-la na operação historiográfica realizada pelo historiador, no ano de 1851. Nesta ocasiáo, Varnhagen compila, estabelece e publica o relato de Gabriel Soares de Sousa, tornando-o uma fonte legítima para a escrita da história. ${ }^{54}$ Nesse trabalho de crítica documental, o historiador tece breves comentários sobre os 270 capítulos do relato do português que viveu em terras americanas no século XVI. Em uma dessas apreciaçôes, logo após a descrição da cidade de Salvador, o historiador assevera: "Ao lermos esta parte da descripção da cidade, quando aportamos na Bahia em principio de Maio d'este anno, quasi que acompanhavamos o autor passo a passo; tanta verdade há em sua descripção". 55

Essa sumária observaçáo de Varnhagen sobre a descrição da paisagem expressa por Soares de Sousa é determinante para este artigo. Como se nota, o historiador sugere que o procedimento permite ao leitor recuperar a paisagem com fidelidade. E esse reconhecimento pode ser realizado mesmo depois de transcorridos mais de 250 anos entre o relato original e o trabalho de crítica documental. Isso demonstra, entâo, como as dimensóes do tempo

\footnotetext{
${ }^{49}$ KOSELLECK, Reinhart. Futuro passado, op. cit., p. 135.

${ }^{50}$ Ibid., p. 133.

${ }^{51}$ Ibid., p. 136.

52 Ibid., p. 138.

${ }^{53}$ Não se trata, evidentemente, de equivaler evento e tempo ou estrutura e espaço. São vetores que atuam em níveis diferentes. No entanto, é importante destacar que a estrutura carrega duas propriedades também assinaláveis ao espaço, a saber, a condição de possibilidade e a duração extensa. Neste sentido, e é isto que tento demonstrar, a paisagem pode ser caracterizada como estrutural.

${ }^{54}$ CEZAR, Temístocles. Quando um manuscrito torna-se fonte histórica. As marcas de verdade no relato de Gabriel Soares de Sousa (1587). Ensaio sobre uma operação historiográfica. História em Revista, Pelotas, v. 6, dez., 2000, p. 39.

${ }^{55}$ VARNHAGEN, Francisco Adolfo de. Tratado Descriptivo do Brazil, em 1587, obra de Gabriel Soares de Souza. Revista do IHGB, Rio de Janeiro, t. 14, 1973 [1851], p. 380-381.
} 
e do espaço se coadunam nas descriçóes. Igualmente, Varnhagen expressa como o evento imiscui-se na estrutura. ${ }^{56}$ Assim, seria possível tomar uma descrição do Tratado Descriptivo do Brazil por guia do território e, inclusive, segui-la de perto, na medida em que sua precisão expressa o espaço com perfeição. Aqui, de certa forma, tempo e espaço são imobilizados e se destaca a continuidade entre o passado e o presente. Se, momentaneamente, desfizéssemos as amarras que isolam tempo/espaço e evento/estrutura em níveis de análise diferentes, seria possível conceber, nesse caso, um espaço estrutural e, algo menos corriqueiro na história moderna, um tempo estrutural. ${ }^{57} \mathrm{~A}$ cápsula do tempo (que abarca o espaço) do futuro passado ganha, pois, uma ilustração.

Por isso é possível sustentar que os enunciados descritivos não são meros quadros intercalados aos textos das obras historiográficas. De modo diverso, o procedimento tem um lugar específico dentro das narrativas. Sua disposição é refletida e isso corrobora a percepção de que as descriçôes participam da própria organização do argumento historiográfico. No caso de Varnhagen, a técnica responde a uma lógica interna da obra, ou seja, ao próprio desenvolvimento diacrônico da história. De acordo com Koselleck, "as estruturas não se tornam grandezas extratemporais; ao contrário, elas adquirem frequentemente um caráter processual - que pode também se integrar às experiências dos eventos cotidianos" ${ }^{58}$ Assim, a estrutura desvela uma funcionalidade. É nela que a narraçáo dos eventos adquire sentido. E, acrescenta Koselleck, muitas vezes a estrutura se integra aos eventos. Se mantivermos as amarras soltas, será possível compreender o papel que a paisagem desempenha na obra de Varnhagen. O historiador defende a importância da descrição do espaço como um preâmbulo à narração dos eventos. Eis, portanto, a função adquirida pela estrutura, afinal, muitas vezes, a pintura da natureza se integra aos próprios eventos. Por isso, tempo e espaço requerem amiúde um tratamento unitário.

\section{O "theatro" da nação}

Sugeri anteriormente que a descrição participa da argumentação historiográfica e, assim, fornece subsídios para a conformação do território. De qualquer forma, vejamos agora como Varnhagen apreende o espaço da nação. Tomo como ilustração desse procedimento a seção

\footnotetext{
${ }^{56}$ Koselleck adverte, contudo, que a integração entre evento e estrutura jamais é total. KOSELLECK, R. Futuro passado, op. cit., p. 139.

${ }^{57}$ Marshall Sahlins aborda exatamente este ponto. O antropólogo reconhece que o pensamento ocidental considera estabilidade e mudança como categorias antitéticas. Desta forma, a história, vista como mudança, não poderia contemplar a estrutura. SAHLINS, M. Ilhas de história. Rio de Janeiro: Jorge Zahar Editor, 1990, p. 180. A fim de desafiar essa percepção, Sahlins cunha a categoria da "estrutura da conjuntura". Ibid., p. 160. Não se trata aqui de aprofundar a reflexão, mas de apontar a possibilidade de pensar em uma história e um tempo estruturais.

${ }^{58}$ KOSELLECK, Reinhart. Futuro passado, op. cit., p. 136.
} 
XLI do segundo volume da Historia geral do Brazil. Aqui, o historiador aborda, entre outros pontos, a colonização das províncias sulistas do império:

E para que desde já tenhamos idea deste local, que dahi a pouco menos e a pouco mais de um terço de seculo devia por duas vezes ser theatro de graves contendas guerreiras entre Portugal e Hespanha, cumpre que nelle nos detenhamos alguns momentos, o que faremos com tanta mais razáo quanto que foi desta paragem que proveiu o nome a toda a provincia, das mais bellas e florescentes do Imperio. ${ }^{99}$

Varnhagen se preocupa em justificar a introdução do espaço em meio à narrativa: o território em questão se tornará, em breve, relevante para o relato histórico, por isso é fundamental que o leitor, desde já, o (re)conheça. Deste modo, o espaço, a descrição, antecede os eventos, a narrativa. Os dois procedimentos se complementam. Um índice dessa complementaridade é justamente o emprego do vocábulo "theatro". Presente no fragmento acima, a expressão é recorrente na Historia geral do Brazil - recorrência que, aliás, demonstra a importância da delimitação do espaço na narrativa historiográfica. Esse vocabulário é compartilhado por outros integrantes do IHGB, como Cunha Barbosa:

A Geographia, como escreve o sabio Ritter, não póde dispensar-se da coadjuvação da Historia, porque não póde deixar de ser uma sciencia real das relaçôes do nosso globo com o espaço; da mesma sorte que a Historia, occupando-se da successão dos acontecimentos no tempo, tem necessidade de um theatro, em que se operão os factos que relata. O objecto da Geographia é o estudo da superficie da terra [...]. A superficie da terra é o theatro da actividade do homem; ella se modifica debaixo da sua acção, e com elle está em uma relação eterna. ${ }^{60}$

A noção de "theatro", uma metáfora, tem como acepção o espaço no qual os acontecimentos irão se desenrolar. Assim, se a descrição da paisagem é uma forma de formular a imagem da nação, Varnhagen vale-se igualmente de uma metáfora que remete ao aspecto visual da narrativa para engendrar esse quadro. Isso porque, se vista sob o ângulo do receptor do procedimento, a expressáo é capaz de transformar a categoria de leitor em algo muito mais complexo e elaborado, na medida em que o "theatro" pressupóe um público, um espectador que assiste à representação dos acontecimentos.

Afinal, o "theatro" carrega consigo, tanto na acepção do Vocabulário de Bluteau quanto na entrada do Dicionário de Moraes Silva, a dimensão da visualidade. Reproduzo-as: "Derivase do Grego Theatis, que quer dizer Espectador. He o lugar em que se ajuntáo os que

\footnotetext{
${ }^{59}$ VARNHAGEN, Francisco Adolfo de. Historia geral do Brazil [...], op. cit., 1857, p. 151.

${ }^{60}$ CUNHA BARBOSA, Januário da. Relatório do secretário perpétuo. Revista do IHGB, Rio de Janeiro, t. 2, 1916 [1840], p. 587-588.
} 
querem ver Tragedias, Comedias, \& outros semelhantes espectaculos". ${ }^{61}$ Já no Moraes Silva, a definição é a seguinte: "Lugar onde se representão dramas, e onde se assiste a representação deles”. ${ }^{62}$ Destarte, o emprego desse vocábulo não parece aleatório. Recordemos que inúmeras reflexóes acerca do uso da cor local nasceram das críticas e debates sobre a dramaturgia. Talvez o aspecto fundamental aqui seja justamente a potencialidade imagética do dispositivo. Afinal, a noção da visualização inerente ao "theatro" pode ser vista como uma forma, inclusive, de solucionar impasses e resolver questóes relativas à interpretação histórica dos acontecimentos. O próprio Varnhagen advogava isso: ao tratar da guerra contra os holandeses, o historiador atenta para as atuaçóes exemplares dos personagens do conflito. Afirma, contudo, que os detalhes de tais eventos não caberiam em uma história que se pretende geral. Mas acrescenta:

[...] e se algum dia a sorte nos guiar os passos ás provincias de Pernambuco e Alagôas, de modo que as possamos por algum tempo percorrer em todos os sentidos, e ver por nosssos proprios olhos o theatro desta prolongada guerra, e estudar os antigos campos de batalha, [...] talvez que emprehendamos tratar o assumpto com mais extensão em uma historia especial, que em tal caso chamariamos da guerra dos vinte e quatro annos. ${ }^{63}$

A presença do historiador no "theatro" dos acontecimentos, desta forma, lhe permite obter subsídios para uma história mais detalhada e precisa. A proximidade confere, enfim, maior fidelidade à tarefa do historiador. Ora, esta postura caracteriza a autópsia, procedimento corrente na escrita da história antiga, mas ainda atuante na historiografia oitocentista. Se a visão auxilia o historiador na escrita da história, é possível pensar que a metáfora teatral contribui para que o leitor, de forma figurada, veja o passado. A cor local é uma metáfora, lembremos, e se realiza/manifesta por meio de outras metáforas. Creio ser válido pensar o "theatro", então, como pertencente à "retórica pictórica”. Assim, a expressão pode ser concebida como uma "autópsia vicária" ou de segundo grau na qual o receptor da descrição se transforma em espectador dos acontecimentos ou da paisagem relatada. Eis, portanto, uma diferença significativa: se a autópsia é um recurso direcionado para o historiador e transmite maior fidelidade na execução de seu ofício, a "autópsia vicária" torna-se uma faculdade voltada para o leitor da narrativa. $\mathrm{O}$ objetivo parece ser, justamente, transportar a noção de fidelidade, de modo a reduplicá-la e assegurar tanto a veracidade da narrativa quanto a crença do leitor. ${ }^{64}$

${ }^{61}$ BLUTEAU, Raphael. Vocabulario portuguez \& latino: aulico, anatomico, architectonico [...]. Coimbra: Collegio das Artes da Companhia de Jesus, t. 8, 1721, p. 149.

${ }^{62}$ MORAES SILVA, Antonio de. Diccionario da lingua portugueza - recompilado dos vocabularios impressos ate agora, e nesta segunda edição [...]. Lisboa: Typographia Lacerdina, 1813, v. 2, p. 773.

${ }^{63}$ VARNHAGEN, Francisco Adolfo de. Historia geral do Brazil [...], op. cit., 1854, p. 361.

${ }^{64}$ Afinal, é necessário atentar para a hipótese sugerida por Fernando Nicolazzi na qual a legitimidade da escrita historiográfica não deriva unicamente dos procedimentos escriturários empregados pelos historiadores, mas também da articulação entre prática escrita e ato de leitura. NICOLAZZI, F. Como se deve ler a 
Torna-se relevante relatar que a conversão do leitor em espectador, a "autópsia vicária", não está desprovida de precedentes. Ao contrário, a escrita da história recorreu inúmeras vezes a esse procedimento. Mark Salber Phillips demonstra, por exemplo, ao abordar a questáo da distância na historiografia, que pensadores como Hume e Lord Kames defendiam diferentes formas de aproximação com o objeto narrado. Este último, refletindo sobre os meios para difundir a educação moral para a sociedade, advogava o emprego do princípio estético da "ideal presence". ${ }^{5}$ Para Lord Kames, escritores sensíveis "representam toda coisa como diante de nossa visão; e de leitores e ouvintes, nos transformam, por assim dizer, em espectadores [...]". ${ }^{66}$ Os românticos iriam então, no século seguinte, aprofundar o desejo de imediação. ${ }^{67}$

No estudo que empreende sobre a retórica renascentista e suas raízes clássicas, Quentin Skinner informa que os oradores mais persuasivos são aqueles que transformam os ouvintes em espectadores. ${ }^{68}$ Para Quintiliano, referência nesse momento, a capacidade de visualização atua como uma forma de convencimento do público, fazendo-o partilhar da posição do orador. Em outras palavras, a visão produz convencimento e crença. Por isso o investimento do orador na busca desse efeito visualizante. Antes de Quintiliano, Políbio almejava algo semelhante e resumia sua intenção na expressão sunopsis, cujo significado era "ver em conjunto" ou "ver tudo simultaneamente" ${ }^{69}$ Hartog entâo resume a potencialidade da epistemologia polibiana: "A sunopsis, enfim, é o resultado: aquilo que o historiador faz ver ao leitor, a evidência, ao produzir uma narrativa sinóptica". ${ }^{70}$

Ora, duas advertências tornam-se imperativas nesta discussão. Inicialmente, é necessário reconhecer a distância desta estrutura retórica para os preceitos epistemológicos que regem a escrita da história no século XIX. Contudo, é evidente que há coincidências, para não dizer semelhanças, entre os dois pressupostos. O uso da cor local também expressa, como tento demonstrar, esse anseio por um contato direto com o passado. Um dos objetivos dessa imediação é justamente reduplicar a fidelidade do relato, tal como ocorria com o modelo retórico antigo. Ademais, como tentei sugerir em relação a Varnhagem, sua descrição da natureza é enriquecida e comovente porque essa é (ou deveria ser) a reação daquele indivíduo que a contempla. O historiador objetivava que o leitor também partilhasse dessa comoção

história? Leitura e legitimação na historiografia moderna. Varia Historia, Belo Horizonte, v. 26, n. 44, jul./ dez., 2010, p. 525. Tal investigação permite - eis a conclusão do artigo - "levar em consideração que, ao se falar em escrita da história, não se deve perder de vista que esta história também é lida e que o ato de leitura ali implicado é parte constitutiva do que se pode chamar conhecimento histórico”. Ibid., p. 544-545.

${ }^{65}$ PHILLIPS, Mark Salber. On historical distance. New Haven: Yale University Press, 2013, p. 91.

${ }^{66}$ KAMES, Lord apud PHILLIPS, Mark S. On historical distance, op. cit., p. 91. "represent every thing as passing in our sight; and from readers or hearers, transform us, as it were, into spectators [...]".

${ }^{67}$ Ibid., p. 95.

${ }^{68}$ SKINNER, Quentin. Razão e retórica na filosofia de Hobbes. São Paulo: Unesp, 1997, p. 252.

${ }^{69}$ HARTOG, François. Evidência da história: o que os historiadores veem. Belo Horizonte: Autêntica, 2011, p. 107.

${ }^{70}$ Ibid., p. 107. 
- o que aponta mais uma semelhança entre os dois dispositivos, antigos e modernos, aqui citados. Para despertar as emoçôes no leitor, entâo, o discurso deve conter imagens que permitam a visualização do que é narrado. E as metáforas, contidas na "retórica pictórica", são um dos principais instrumentos para esse escopo. Enfim, com a cor local o leitor vê e sente. Temos, pois, a "autópsia vicária".

É necessário ratificar - eis a segunda advertência - que esse processo é figurado. Existem tentativas de compreender essa transferência da palavra para a visão e inclusive explicar essa espécie de sinestesia. É possível, então, sugerir motivaçôes, estratégias e desdobramentos; contudo, o processo é, do ponto de vista de sua concretização, insondável. Michel Foucault sintetiza: "por mais que se diga o que se vê, o que se vê não se aloja jamais no que se diz, e por mais que se faça ver o que se está dizendo por imagens, metáforas, comparaçôes, o lugar onde estas resplandecem não é aquele que os olhos descortinam, mas aquele que as sucessôes da sintaxe definem". ${ }^{71}$

De certa forma, este artigo encerra um ciclo. Afinal, o "theatro" (espaço da nação) expresso pela cor local coaduna-se com o teatro (dramaturgia) do qual o dispositivo colheu propriedades significativas e que encetou esta abordagem. Esta relação, creio, não é ocasional. A dramaturgia e, de modo mais amplo, a literatura testemunham modificaçóes nesse período, assumindo suas formulaçôes modernas. A cor local adquire, a partir da fusão desta tradição com influxos mais antigos, valores como observação fidedigna, imaginação e abarca dimensôes como o tempo e o espaço. Estas qualidades dirigem-se para a representação do grande tema que se constitui nesse momento: a nação. Em processo de consolidação, o Estado nacional requer a delimitação de um tempo e espaço próprios. A cor local, empregada em diferentes meios representacionais, participa desta construçáo. $\mathrm{Na}$ escrita da história seu emprego é múltiplo: ela possibilita apreender um tempo específico, delimitar um espaço determinado e, ainda, assegurar a fidelidade da narrativa por meio de efeitos que permitem não só ao historiador, mas também ao leitor, ver e verificar o passado e a paisagem, isto é, as imagens que constituem a nação.

\section{Fontes}

BLUTEAU, Raphael. Vocabulario portuguez \& latino: aulico, anatomico, architectonico [...]. Coimbra: Collegio das Artes da Companhia de Jesus, t. 8, 1721.

\footnotetext{
${ }^{71}$ FOUCAULT, Michel. As palavras e as coisas: uma arqueologia das ciências humanas. São Paulo: Martins Fontes, 2007, p. 12.
} 
CONSTANT, Benjamin. Réflexions sur la tragédie [...]. Revue de Paris, Bruxelas, t. 7, p. $132-147,1829$.

CUNHA BARBOSA, Januário da. Discurso. Revista do IHGB, Rio de Janeiro, t. 1, p. 9-17, 1908 [1839].

. Relatório do secretário perpétuo. Revista do IHGB, Rio de Janeiro, t. 2, p. 582603, 1916 [1840].

Dictionary of literary terms. Toronto: Coles Publishing Company, c. 1963.

D’AVEZAC, Armand. Considérations géographiques sur l'Histoire du Brésil. Examen critique d'une nouvelle Histoire Générale du Brésil. Paris: Imprimerie de L. Martinet, 1857.

MARTIUS, Karl Friederich Phillipe von. Como se deve escrever a História do Brazil. Revista do IHGB, Rio de Janeiro, t. 6, p. 381-403, 1973 [1844].

MORAES SILVA, Antonio de. Diccionario da lingua portugueza - recompilado dos vocabularios impressos ate agora, e nesta segunda edição [...]. Lisboa: Typographia Lacerdina, 1813, v. 2.

STAËL, Madame de. De L'Allemagne. In: Oeuvres complètes de Mme. la baronne de Staël. Paris: L'Imprimerie de Plassan, t. 11, 1820.

VARNHAGEN, Francisco Adolfo de. Tratado Descriptivo do Brazil, em 1587, obra de Gabriel Soares de Souza. Revista do IHGB, Rio de Janeiro, t. 14, p. 13-423, 1973 [1851]. . Historia geral do Brazil [...]. Rio de Janeiro: E. H. Laemmert, 2 tomos, 18541857.

\section{Referências bibliográficas}

ARAUJO, Valdei. A experiência do tempo: conceitos e narrativas na formação nacional brasileira (1813-1845). São Paulo: Hucitec, 2008.

- Observando a observação: a descoberta do Clima Histórico e a emergência do cronótopo historicista, c. 1820. In: CARVALHO, José Murilo; CAMPOS, Adriana Pereira (Orgs.). Perspectivas da cidadania no Brasil Império. Civilização Brasileira: Rio de Janeiro, 2009, p. $281-303$.

CANDIDO, Antonio. Literatura e sociedade. Rio de Janeiro: Ouro sobre azul, 2006.

CARLOS, Lilian. Uma relaçâo a dois: a história e a geografia nos primeiros anos do Instituto Histórico e Geográfico Brasileiro. Dissertação (mestrado em História). São Leopoldo: Unisinos, 2008.

CEZAR, Temístocles. Quando um manuscrito torna-se fonte histórica. As marcas de verdade 
no relato de Gabriel Soares de Sousa (1587). Ensaio sobre uma operação historiográfica. História em Revista, Pelotas, v. 6, p. 37-58, dez., 2000.

- A geografia servia, antes de tudo, para unificar o Império. Escrita da história e saber geográfico no Brasil oitocentista. Ágora, Santa Cruz do Sul, v. 11, n. 1, p. 79-99, jan./ jun., 2005.

Anciens, Modernes et Sauvages, et l'écriture de l'histoire au Brésil au XIX siècle. Le cas de l'origine des Tupis. Anabases, Toulouse, n. 8, p. 43-65, 2008.

COUTINHO, Afrânio (Org.). A polêmica Alencar/Nabuco. Rio de Janeiro: Tempo Brasileiro; Brasília: Editora UnB, 1978.

FLUCKIGER, Carine. L'histoire entre art et science: la "couleur locale" chez Thierry et Barante. Mémoire de licence. Université de Genève, 1995.

FOUCAULT, Michel. As palavras e as coisas: uma arqueologia das ciências humanas. São Paulo: Martins Fontes, 2007.

HAMON, Philippe. Du Descriptif. Paris: Hachette Livre, 1993.

HARTOG, François. Evidência da história: o que os historiadores veem. Belo Horizonte: Autêntica, 2011.

KAMERBEEK, Jan. Couleur. In: ESCARPIT, Robert. Dictionnaire international des termes littéraires. Berne: A. Francke, 1986, p. 397-400.

KAPOR, Vladimir. Exotisme et couleur locale — essai d'une analyse constrastive des champs sémantiques respectifs. Conference Paper. Proceedings, France and the Exotic, University of Birmingham, UK, p. 1-11, 2003. Local colour: a travelling concept. Bern: Peter Lang AG, 2009.

KOSELLECK, Reinhart. Los estratos del tiempo: estudios sobre la historia. Barcelona: Paidós, 2000.

- Futuro passado. Contribuição à semântica dos tempos históricos. Rio de Janeiro: Contraponto/Editora PUC-Rio, 2006.

MALAKIS, Emile. The First Use of Couleur Locale in French Literary Criticism. Modern Language Notes, Baltimore, v. 60, n. 2, p. 98-99, feb., 1945.

MORETTI, Franco. The bourgeois: between literature and history. Londres; Nova York: Verso, 2013.

NICOLAZZI, Fernando. Como se deve ler a história? Leitura e legitimação na historiografia moderna. Varia Historia, Belo Horizonte, v. 26, n. 44, p. 523-545, jul./dez., 2010.

PEIXOTO, Renato. A máscara da medusa: a construção do espaço nacional brasileiro através das corografias e da cartografia no século XIX. Tese (doutorado em História). Rio de Janeiro: Universidade Federal do Rio de Janeiro, 2005. 
PHILLIPS, Mark Salber. On historical distance. New Haven: Yale University Press, 2013.

ROUANET, Maria Helena. Eternamente em berço esplêndido: a fundaçâo da literatura nacional. São Paulo: Siciliano, 1991.

SAHLINS, Marshall. Ilhas de história. Rio de Janeiro: Jorge Zahar Editor, 1990.

SKINNER, Quentin. Razão e retórica na filosofia de Hobbes. São Paulo: Unesp, 1997.

SÜSSEKIND, Flora. O Brasil não é longe daqui: o narrador, a viagem. São Paulo: Companhia das Letras, 1990. 